\title{
Selective Cumulative Inhibition of Platelet Thromboxane Production by Low-dose Aspirin in Healthy Subjects
}

\author{
Paola Patrignani, Paola Filabozzi, and Carlo Patrono, Department of \\ Pharmacology, Catholic University School of Medicine, 00168 Rome, Italy
}

A B S T R A C T Acetylation of platelet cyclooxygenase by oral aspirin is dose dependent and cumulative with repeated administration. However, no single dose of aspirin has been found to be completely selective of platelet thromboxane (TX) synthesis inhibition in man. We determined the dose dependence, cumulative nature and selectivity of aspirin effects on platelet $\mathrm{TXB}_{2}$ and renal prostaglandin (PG) and prostacyclin $\left(\mathrm{PGI}_{2}\right)$ production. We measured, by radioimmunoassay, serum $\mathrm{TXB}_{2}$ levels after whole blood clotting and urinary excretion of $\mathrm{PGE}_{2}, \mathrm{PGF}_{2 \alpha}$, and 6-keto-PGF $\mathrm{PG}_{1 \alpha}$, before and after single or repeated oral aspirin doses given to 46 healthy subjects. Single doses of $6-100 \mathrm{mg}$ aspirin resulted in a linear $(r=0.92, P<0.01)$ inhibition of platelet $\mathrm{TXB}_{2}$ production, ranging from 12 to $95 \%$ after $24 \mathrm{~h}$. A daily dose of $0.45 \mathrm{mg} / \mathrm{kg}$ given for $7 \mathrm{~d}$ produced a cumulative and virtually complete inhibition of platelet $\mathrm{TXB}_{2}$ production, without significantly reducing the urinary excretion of $\mathrm{PGE}_{2}$, $\mathrm{PGF}_{2 \alpha}$, and 6-keto-PGF $\mathrm{F}_{1 \alpha}$ in both healthy men and women. The platelet inhibitory effect of this regimen was maintained unaltered throughout 1 mo of therapy, with no evidence of cumulative inhibition of renal PGsynthesis. Moreover, furosemide-induced renal $\mathrm{PGI}_{2}$ synthesis and renin release were unaffected by chronic low-dose aspirin. Following cessation of aspirin therapy, platelet $\mathrm{TXB}_{2}$ production returned toward control values at a similar rate as after a single higher dose.

We conclude that in healthy subjects: $(a)$ aspirin causes a dose-dependent inhibition of platelet $\mathrm{TXA}_{2}$ production, with no obvious sex-related difference; (b) the inhibitory effect of daily low-dose aspirin is cumulative on platelet $\mathrm{TXA}_{2}$ but not on renal PG-synthesis; $(c)$ during chronic low-dose aspirin therapy, renal $\mathrm{PGI}_{2}$-producing cells are readily activable by furosemide at a time of virtually complete suppression of platelet cyclooxygenase activity.

This work was presented in part at the Annual Meeting of the American Federation for Clinical Research, 27 April 1981, San Francisco, CA. (1).

Received for publication 21 July 1981 and in revised form 5 February 1982.

\section{INTRODUCTION}

Aspirin acetylates the active site of cyclooxygenase (2), the enzyme converting arachidonic acid into the prostaglandin $(\mathrm{PG})^{1}$ cyclic endoperoxides, thereby reducing their further transformations into stable and unstable biologically active compounds, i.e. PG, prostacyclin $\left(\mathrm{PGI}_{2}\right)$ and thromboxane $(\mathrm{TX}) \mathrm{A}_{2}$. Reduced formation of these metabolites in different target tissues can probably account for the wide variety of pharmacologic effects of the drug, which form the basis of its therapeutic use and its toxicity (3). Thus, the use of aspirin as an antithrombotic agent is predicated on the assumption that blockade of the cyclooxygenase pathway of platelet arachidonic acid metabolism favorably affects pathological thrombosis by virtue of a reduced $\mathrm{TXA}_{2}$ formation. However, doses of the drug in the range of $300-1,500 \mathrm{mg}$ also cause a variable inhibition of the same pathway in vascular tissue (4), gastric mucosa (5), and renal tissue (6). The functional consequences of these extra platelets effects of aspirin are currently held responsible for reduced antithrombotic activity, increased incidence of gastric erosions and reduced renal function in some patients (3). Numerous attempts have been made in recent years in order to find an ideal dose of aspirin that would inhibit cyclooxygenase in platelets but not in other tissues, particularly in the vessel wall. However, most human studies, based on single-dose experiments, have failed to demonstrate the existence of such a "therapeutic window."

The aims of the present investigation were: $(a)$ to characterize the dose dependence of aspirin effect on platelet $\mathrm{TXA}_{2}$ formation in healthy subjects, in order to define low-dose vs. high-dose for this particular effect of the drug; (b) to determine whether cumulative inhibition of platelet TXA formation by daily administration of low-dose aspirin would also affect the cy-

\footnotetext{
${ }^{1}$ Abbreviations used in this paper: PG, prostaglandin (used variously according to the identification of a given prostaglandin, i.e. $\mathrm{PGE}_{2}$ or $\mathrm{PGI}_{2}$ ); RIA, radioimmunoassay; TX, thromboxane.
} 
clooxygenase pathway of renal arachidonic acid metabolism, i.e., a well recognized target of aspirin toxicity; $(c)$ to measure the long-term effects of this potential therapeutic regimen on platelet and renal PG formation and to characterize the recovery pattern of cyclooxygenase activity upon discontinuing the drug.

The results of this study demonstrate that a daily dose of aspirin as low as $0.45 \mathrm{mg} / \mathrm{kg}$ causes a cumulative inhibition of platelet $\mathrm{TXA}_{2}$ formation without interfering with renal PG synthesis in healthy subjects.

\section{METHODS}

Subjects. A total of $\mathbf{4 6}$ healthy volunteers were studied (7 male, M; 39 female, F; ages 18-37 yr). They were students, nurses and graduates of the Catholic University Medical School, who gave their informed consent to participate in this study. A careful interview was entertained with each of them in order to exclude the intake of nonsteroidal antiinflammatory drugs during the $2 \mathrm{wk}$ preceding each phase of the study. Several subjects were studied repeatedly.

Single-dose study. To establish the dose-response relation for the inhibitory effect of aspirin on platelet $\mathrm{TXA}_{2}$ production, 4-14 volunteers were randomly allocated to different treatment groups i.e., $6,12,25,50$, and $100 \mathrm{mg}$. Aspirin capsules were prepared by directly weighing acetylsalicylic acid (Bayer AG, Leverkusen, West Germany). 3-5-ml peripheral blood samples were drawn by venipuncture, in the fasting state, before, and $24 \mathrm{~h}$ after oral aspirin administration. Platelet $\mathbf{T X A}_{2}$ production during whole blood clotting was studied as described below.

Multiple-dose studies. In nine subjects $(4 \mathrm{M}$, age $36.3 \pm 0.5$ $\mathrm{yr}$, weight $74.8 \pm 10.2 \mathrm{~kg} ; 5 \mathrm{~F}$, age $27.4 \pm 4.3 \mathrm{yr}$, weight $50.8 \pm 7.2 \mathrm{~kg}$; mean $\pm \mathrm{SD}$ ) the effects of daily $20-40 \mathrm{mg}$ doses of the drug were investigated on platelet $\mathrm{TXA}_{2}$ formation and urinary $\mathrm{PGE}_{2}, \mathrm{PGF}_{2 \alpha}$, and 6-keto- $\mathrm{PGF}_{1 \alpha}$ (the stable breakdown product of $\mathrm{PGI}_{2}$ ) excretion. For this purpose, blood and urine samples were collected daily during 1 control wk and during 1 wk of aspirin therapy $(0.45 \pm 0.03 \mathrm{mg} /$ $\mathrm{kg}$ per $\mathrm{d}$; mean $\pm \mathrm{SD}$ ). 1 mo after completion of the study, two female subjects underwent $1 \mathrm{wk}$ of aspirin treatment at a dose of 0.5 and $1.0 \mathrm{~g}$ daily $(10.2$ and $17.5 \mathrm{mg} / \mathrm{kg}$ per $\mathrm{d}$, respectively), and blood and urine samples were collected similarly.

In order to demonstrate long-term maintenance and selectivity of the cumulative inhibitory effect of low-dose aspirin, three of the same subjects $(1 \mathrm{~F}, 2 \mathrm{M}$; age $33 \pm 6.7 \mathrm{yr}$ ) underwent aspirin treatment $(0.45 \pm 0.02 \mathrm{mg} / \mathrm{kg}$ per d) for $1 \mathrm{mo}$. Blood samples were drawn three times weekly, the week before starting treatment, the 2nd, 3rd, and 4th wk of treatment, and the 2 nd wk after discontinuing the drug; they were taken daily during the 1st wk of treatment and the lst wk after discontinuing aspirin. Urine samples were collected three times weekly throughout the study. In all multiple-dose studies, aspirin was taken shortly before midnight (immediately after voiding) and urine collected from midnight to $8 \mathrm{a} . \mathrm{m}$. A $100-\mathrm{ml}$ aliquot of the 8 -h collection was frozen immediately after voided and kept at $-20^{\circ} \mathrm{C}$ until extracted. The rationale for 8 -h rather than 24 -h urine collections was: (a) greater reproducibility of urinary PG excretion measured in the same subjects on successive days, because of uniformly standardized conditions; $(b)$ greater chances of detecting a moderate reversible inhibition of renal PG synthesis induced by chronic aspirin intake. Venous blood samples $(3 \mathrm{ml})$ were drawn at 10 a.m., $2 \mathrm{~h}$ after a light breakfast. Platelet $\mathrm{TXA}_{2}$ production in response to endogenous thrombin was studied by letting triplicate $1-\mathrm{ml}$ aliquots of whole blood to clot at $37^{\circ} \mathrm{C}$ for $60 \mathrm{~min}$, as previously described (7). The separated sera were frozen and kept at $-20^{\circ} \mathrm{C}$ until assayed. In addition, the acute effects of furosemide, which is known to induce an immediate overall activation of renal PG synthesis and renin release $(8,9)$, were investigated under control conditions and again during the 3rd and 4th wk of aspirin treatment. For this purpose, a 4$h$ control sample before and three consecutive urine samples after an intravenous injection of furosemide (Lasix, Hoechst AG, Frankfurt, West Germany: $0.64 \pm 0.09 \mathrm{mg} / \mathrm{kg}$ ) were collected and immediately frozen. Samples of peripheral venous blood $(10 \mathrm{ml})$ were drawn into iced tubes containing EDTA, before and 15 and $180 \mathrm{~min}$ after furosemide. The separated plasma was frozen immediately and kept at $-20^{\circ} \mathrm{C}$ until assayed for renin activity.

Analyses. Serum $\mathrm{TXB}_{2}$ (the stable breakdown product of $\mathrm{TXA}_{2}$ ) concentrations were measured by a previously described radioimmunoassay (RIA) technique (10). Unextracted serum samples were diluted in the standard diluent of the assay $\left(0.02 \mathrm{M} \mathrm{PO}_{4}\right.$ buffer, $\left.\mathrm{pH} 7.4\right)$ and assayed in a volume of $1.5 \mathrm{ml}$ at a final dilution of $1: 500-1: 15,000$. The assay uses 5,000 dpm of $\left.{ }^{3} \mathrm{H}\right] \mathrm{TXB}_{2}$ (New England Nuclear, Boston, MA: $150 \mathrm{Ci} / \mathrm{mM}$ ) and a rabbit anti-TXB $\mathrm{T}_{2}$ serum diluted $1: 1,000,000$. The least detectable concentration that can be measured with $95 \%$ confidence (i.e., 2 SD at zero) is $2 \mathrm{pg}$ of $\mathrm{TXB}_{2} / \mathrm{ml}$ of incubation mixture. Therefore, the detection limit of the assay was $1 \mathrm{ng}$ of $\mathrm{TXB}_{2} / \mathrm{ml}$ of serum, i.e., $\sim 0.5 \%$ of the serum $\mathrm{TXB}_{2}$ concentration measured in healthy subjects (7). Validation of $\mathrm{TXB}_{2}$ measurements was obtained by three independent criteria: $(a)$ dilution and recovery studies; $(b)$ characterization of the chromatographic pattern of distribution of extracted $\mathrm{TXB}_{2}$-like immunoreactivity on thin-layer chromatography, as described in detail elsewhere (7); (c) comparison with other anti- $\mathrm{TXB}_{2}$ sera. Two additional anti-TXB ${ }_{2}$ sera were used at final dilutions of $1: 200,000$ and $1: 100,000$, respectively. The $\mathrm{IC}_{50}$ values (concentrations of unlabeled $\mathrm{TXB}_{2}$ required to displace $50 \%$ of bound $\left.\left[{ }^{3} \mathrm{H}\right] \mathrm{TXB}_{2}\right)$ of the three antisera used were: 17,14 , and $15 \mathrm{pg} / \mathrm{ml}$. The cross-reactivities of some relevant arachidonic acid metabolites with the two additional anti- $\mathrm{TXB}_{2}$ sera are described in Table I. Urinary $\mathrm{PGE}_{2}, \mathrm{PGF}_{2 \alpha}$, and 6keto-PGF ${ }_{1 \alpha}$, which reflect, within limits, the renal synthesis of $\mathrm{PGE}_{2}, \mathrm{PGF}_{2 \alpha}(11)$, and $\mathrm{PGI}_{2}(9)$, respectively, were measured by RIA techniques after extraction and silicic acid column chromatography $(12,9)$. Validation of RIA measurements was obtained by several independent criteria, i.e., comparison among multiple anti-PG sera; characterization of the thin-layer chromatography pattern of distribution of the extracted PG-like immunoreactivity; comparison with gas chromatography/mass spectrometry determinations. These techniques are described in detail elsewhere $(12,9)$.

Plasma renin activity was measured by RIA of angiotensin I, as described by Haber et al. (13), using a commercially available kit (Sorin Biomedica, Saluggia, Italy).

Results were subjected to analysis of variance and Student's $t$ test.

\section{RESULTS}

In 33 healthy subjects, who were studied before and $24 \mathrm{~h}$ after single aspirin administrations, serum $\mathrm{TXB}_{2}$ concentrations averaged $228 \pm 87 \mathrm{ng} / \mathrm{ml}$ (mean $\pm \mathrm{SD}$ ) in the control state. The lowest single dose of aspirin causing a statistically significant reduction $(31 \pm 15 \%$, 
TABLE I

Immunological Specificity of Antisera Directed against $\mathrm{TX}_{2}$

\begin{tabular}{|c|c|c|}
\hline \multirow[b]{2}{*}{ Substance measured } & $\begin{array}{c}\text { AS } \\
2\end{array}$ & $\begin{array}{c}\text { AS } \\
3\end{array}$ \\
\hline & \multicolumn{2}{|c|}{ Relative cross-reaction } \\
\hline & \multicolumn{2}{|c|}{$\%$} \\
\hline $\mathrm{TXB}_{2}$ & 100 & 100 \\
\hline 2,3-dinor-TXB ${ }_{2}$ & 1.3 & 2.0 \\
\hline $\mathrm{PGF}_{2 \alpha}$ & 0.3 & 0.5 \\
\hline $\mathrm{PGD}_{2}$ & 0.03 & 0.05 \\
\hline 2,3-dinor-6-keto-PGF ${ }_{1 \alpha}$ & 0.01 & 0.03 \\
\hline $\mathrm{PGE}_{2}$ & 0.005 & 0.003 \\
\hline 6-keto-PGF $1 \alpha$ & 0.002 & 0.004 \\
\hline $13,14-\mathrm{DH}-6,15-\mathrm{DK}-\mathrm{PGF}_{1 \alpha}$ & $<0.001$ & $<0.002$ \\
\hline 6-keto-PGE 1 & $<0.001$ & $<0.002$ \\
\hline $\mathrm{LTC}_{4}$ & $<0.001$ & $<0.002$ \\
\hline $\mathrm{LTD}_{4}$ & $<0.001$ & $<0.002$ \\
\hline
\end{tabular}

AS, antisera.

LT, leukotriene.

$P<0.01$ ) of serum $\mathrm{TXB}_{2}$ concentrations was $12 \mathrm{mg}$. As shown in Fig. 1, oral aspirin administration caused a dose-dependent inhibition of platelet $\mathrm{TXB}_{2}$ production, achieving virtually complete suppression of cyclooxygenase activity at $100 \mathrm{mg}(95 \pm 4 \%$ inhibition). A statistically significant correlation was found between the aspirin dose and percentage reduction of serum $\mathrm{TXB}_{2}$ concentrations $(r=0.92, P<0.01, n$ $=33$ ).

Five control sera and five sera obtained $24 \mathrm{~h}$ after aspirin were subjected to RIA using three different anti-TXB ${ }_{2}$ sera. A statistically significant correlation was found among the three sets of data: $r=0.999$, 0.961 , and $0.963, P<0.001$. The mean coefficient of variation for the whole series was $13.1 \%$, a figure not

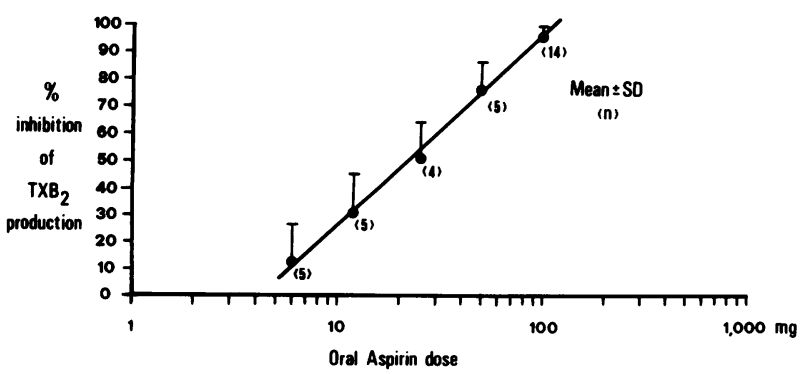

Figure 1 Inhibition of platelet $\mathrm{TXB}_{2}$ production by oral aspirin. $\mathrm{TXB}_{2}$ production during whole blood clotting was measured before and $24 \mathrm{~h}$ after aspirin ingestion. The results are expressed as percent inhibition, each subject serving as his or her own control. Mean values \pm 1 SD are plotted. Numbers in parentheses indicate the number of subjects for each dose of aspirin. significantly different from the $11.1 \%$ value found in a previous study when multiple $1-\mathrm{ml}$ aliquots of the same blood samples were analyzed with the same antiserum (7).

The base-line values of serum $\mathrm{TXB}_{2}$, urinary $\mathrm{PGE}_{2}$, $\mathrm{PGF}_{2 \alpha}$, and 6-keto-PGF $\mathrm{F}_{1 \alpha}$ excretion of five healthy women and four healthy men, measured daily during a 7-d control period, are reported in Table II. No statistically significant differences were found between male and female values of each of the four parameters. The intrasubject variability, measured during 7 consecutive $\mathrm{d}$, averaged $14 \pm 5 \%$ (mean $\pm \mathrm{SD}, n=9)$ for serum $\mathrm{TXB}_{2}$, and $30 \pm 10,19 \pm 5,18 \pm 8 \%$ for urinary $\mathrm{PGE}_{2}, \mathrm{PGF}_{2 \alpha}$, and 6-keto-PGF $1 \alpha$ excretion. Men had a significantly higher coefficient of variation for urinary $\mathrm{PGE}_{2}$ excretion as compared to women: $37 \pm 6$ vs. $24 \pm 9 \%(P<0.025)$. No statistically significant differences were found for the other compounds measured. Urine volume during the 8 - $\mathrm{h}$ collection period $(7.85 \pm 0.9 \mathrm{~h}$ ) averaged $31 \pm 15 \mathrm{ml} / \mathrm{h}$ (mean $\pm \mathrm{SD}, n$ $=63$ ), with no statistically significant difference between men and women. The excretion of $\mathrm{PGE}_{2}, \mathrm{PGF}_{2 \alpha}$, and 6-keto-PGF $\mathrm{P}_{1 \alpha}$ did not correlate with urine volume to any significant extent $(r=0.24,0.26$, and 0.15 , respectively).

As shown in Fig. 2, a daily aspirin dose of $0.45 \mathrm{mg} /$ kg caused a statistically significant $(P<0.005)$ reduction of serum $\mathrm{TXB}_{2}$ concentrations, which averaged $36 \%$ after the first dose, $70 \%$ after the second dose, $87 \%$ after the third dose, and $95 \%$ after the fourth dose. Under the same circumstances, the urinary excretion of renal PG was not affected to any statistically significant extent, in either female or male subjects. The urinary excretion rates of $\mathrm{PGE}_{2}, \mathrm{PGF}_{2 \alpha}$, and 6keto- $\mathrm{PGF}_{1 \alpha}$ averaged $10.8 \pm 4.9 \mathrm{ng} / \mathrm{h}$ (mean $\pm \mathrm{SD}, n$ $=63$ ), $23.9 \pm 9.0$ and $4.7 \pm 2.6$ during the $7-\mathrm{d}$ aspirin period as compared to $10.7 \pm 4.7,20.7 \pm 4.8$, and $4.7 \pm 1.9$, respectively, during the 7 - $d$ control period. Aspirin did not affect urine volume, which averaged $32 \pm 13 \mathrm{ml} /$ $\mathrm{h}$ during a $7-\mathrm{d}$ period. Although the urinary excretion of 6 -keto-PGF - $_{1 \alpha}$ measured during the last $3 \mathrm{~d}$ of aspirin

TABLE II

Mean ( $\pm S D)$ Base-line Values of Serum $\mathrm{TX}_{2}$ Concentration and Urinary $(U) P G E_{2}, P G F_{2 \alpha}$, and 6-Keto-PGF $F_{1 \alpha}$ Excretion, Measured Daily during a 7-d Period in Nine Healthy Subjects (4 M, 5 F)

\begin{tabular}{lccc}
\hline \multicolumn{1}{c}{ Compound measured } & Men & Women & $P$ \\
\hline & $n=28$ & $n=35$ & \\
Serum $\mathrm{TXB}_{2}, n g / m l$ & $321 \pm 55$ & $299 \pm 128$ & NS \\
U-PGE,$n g / h$ & $11.6 \pm 4.5$ & $10.2 \pm 4.9$ & NS \\
U-PGF $_{2 \alpha}, n g / h$ & $20.4 \pm 5.4$ & $21.0 \pm 4.6$ & NS \\
U-6-Keto-PGF $_{1 \alpha}, n g / h$ & $4.8 \pm 2.4$ & $4.6 \pm 1.6$ & NS \\
\hline
\end{tabular}



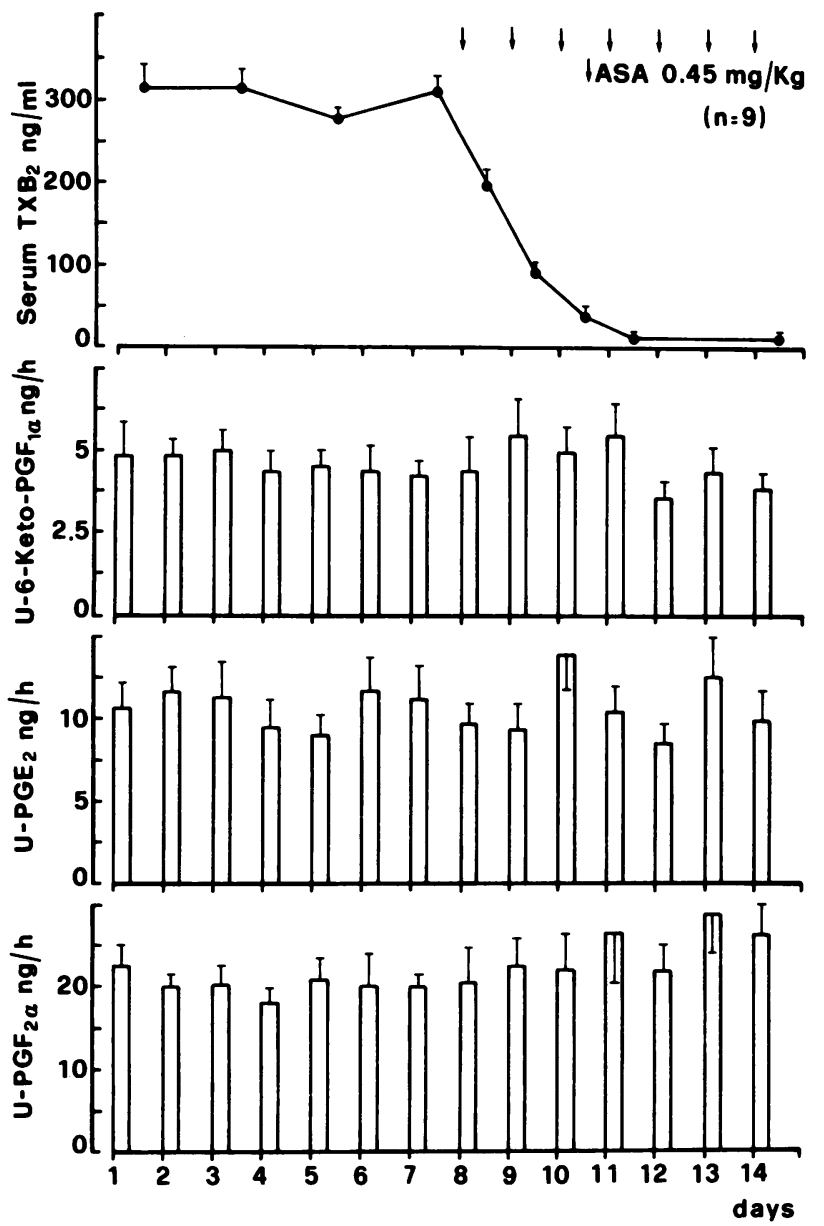

Figure 2 Effect of daily low-dose $(0.45 \mathrm{mg} / \mathrm{kg})$ aspirin on platelet $\mathrm{TXB}_{2}$ and renal PG-synthesis. Serum $\mathrm{TXB}_{2}$ concentrations and urinary excretion of 6-keto-PGF $F_{1 \alpha}, \mathrm{PGE}_{2}$, and $\mathrm{PGF}_{2 \alpha}$ were measured in nine healthy subjects during 7 consecutive control $\mathrm{d}$ and $\mathrm{l}$ wk of aspirin therapy. Mean values \pm SEM are plotted. The arrows indicate daily aspirin intake.

treatment was $\sim 20 \%$ lower than during the first $4 \mathrm{~d}$, this difference did not reach statistical significance. In two of the same subjects who underwent $1 \mathrm{wk}$ of aspirin treatment at doses of 0.5 and $1 \mathrm{~g}$ daily, the urinary excretion of 6-keto-PGF ${ }_{1 \alpha}(2.8 \pm 0.6$ and $1.9 \pm 0.4)$, $\mathrm{PGE}_{2}(6.2 \pm 1.4$ and $4.0 \pm 0.9)$, and $\mathrm{PGF}_{2 \alpha}(12.6 \pm 2.2$ and $8.5 \pm 1.5)$ was significantly $(P<0.01)$ reduced by $\sim 40$ and $60 \%$, respectively, with no evidence of cumulative inhibition as a function of time. The long-term effects of this therapeutic regimen were reassessed in three of the same subjects in order to verify maintenance of the platelet inhibitory effect and to ascertain whether appreciable changes of renal PG synthesis might become apparent on a more chronic basis. As shown in Fig. 3, serum $\mathrm{TXB}_{2}$ showed cumulative in-

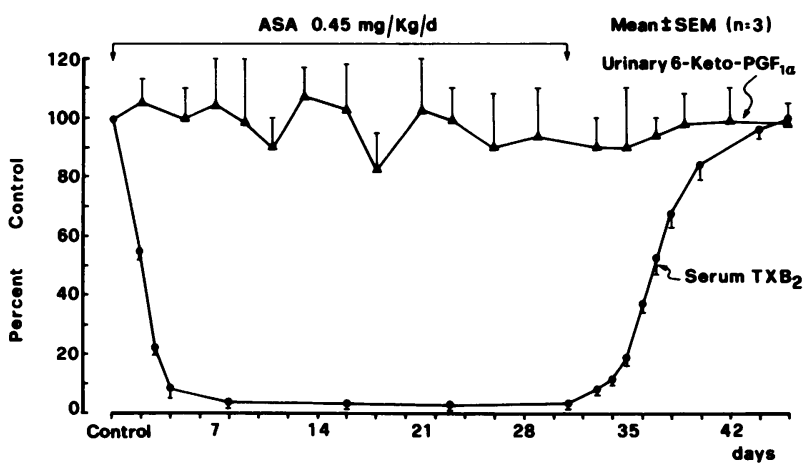

Figure 3 Long-term effects of low-dose $(0.45 \mathrm{mg} / \mathrm{kg}$ per d) aspirin on platelet $\mathrm{TXB}_{2}$ and renal $\mathrm{PGI}_{2}$ synthesis. Serum $\mathrm{TXB}_{2}$ concentrations and urinary excretion of 6-keto- $\mathrm{PGF}_{10}$ were measured in three healthy subjects before, during, and after aspirin therapy. Mean values \pm SEM are plotted. The arrows indicate duration of daily aspirin therapy.

hibition with a pattern substantially similar to the previous study. Greater than $95 \%$ inhibition of platelet $\mathrm{TXB}_{2}$ production was maintained throughout the whole treatment period. Upon discontinuing aspirin, platelet $\mathrm{TXB}_{2}$ production returned with a time course similar to that described following a single $100-\mathrm{mg}$ dose (7) and consistent with platelet turnover and reappearance of unacetylated platelet cyclooxygenase (14). Platelet life-span calculated by linear regression analysis, assuming a 2-d lag period before enzyme recovery (14), a veraged $9.2 \pm 1.6 \mathrm{~d}$ (mean $\pm \mathrm{SD})$. The urinary excretion of 6 -keto-PGF $1 \alpha$ measured during the same period ranged between 82 and $108 \%$ of control values, with no statistically significant changes throughout the whole month. The urinary excretion of $\mathrm{PGE}_{2}$ and $\mathrm{PGF}_{2 \alpha}$ followed a substantially similar pattern (not shown). The excretion rates of 6-keto-PGF ${ }_{1 \alpha}, \mathrm{PGE}_{2}$, and $\mathrm{PGF}_{2 \alpha}$ averaged $4.0 \pm 2.0 \mathrm{ng} / \mathrm{h}$ (mean $\pm \mathrm{SD}, n$ $=36), 13.5 \pm 6.1$ and $34.1 \pm 16.4$ during the $31-\mathrm{d}$ aspirin period as compared with $3.9 \pm 1.9($ mean $\pm \mathrm{SD}, n=27)$, $14.3 \pm 6.3$ and $33.1 \pm 15.6$, respectively, during the 21 d control period.

The fate of plasma renin activity and urinary 6-keto$\mathrm{PGF}_{1 \alpha}$ following the administration of a pharmacologic stimulus known to stimulate renin release through increased renal $\mathrm{PGI}_{2}$ synthesis (9) was investigated by infusing furosemide into the same subjects, under control conditions and during the 3rd and 4th wk of aspirin treatment. As shown in Fig. 4, furosemide caused a statistically significant increase of urinary 6-keto$\mathrm{PGF}_{1 \alpha}$, with a substantially similar pattern under control and chronic aspirin treatment. Under all circumstances, the excretion rate of 6-keto-PGF ${ }_{1 \alpha}$ increased approximately fourfold over basal levels, remained significantly elevated over a period of $60 \mathrm{~min}$ and declined thereafter. Plasma renin activity rose signifi- 


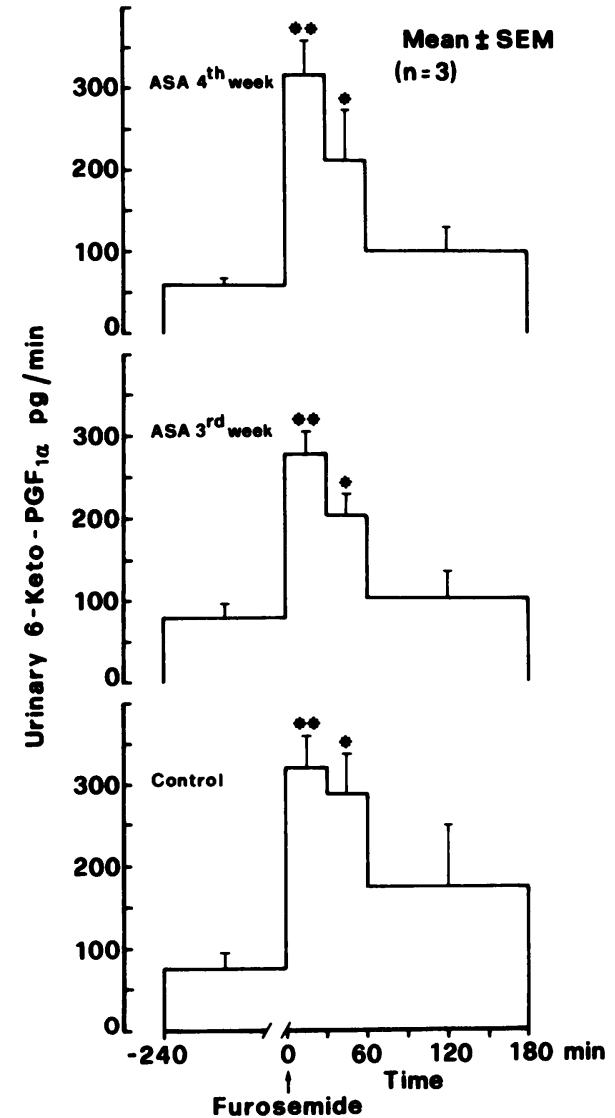

FIGURE 4 Furosemide infusion under control conditions and during low-dose $(0.45 \mathrm{mg} / \mathrm{kg}$ per $\mathrm{d})$ aspirin therapy. The time course of urinary 6-keto-PGF ${ }_{1 \alpha}$ excretion rates following the infusion of furosemide $(0.64 \mathrm{mg} / \mathrm{kg}, \mathrm{i} . \mathrm{v}$.) was measured in three healthy subjects before (the lower panel) and during the 3rd (the middle panel) and 4th (the upper panel) wk of aspirin therapy. Mean values \pm SEM are plotted. The level of significance of the difference between values obtained before and after furosemide was determined by the paired $t$ test. ${ }^{\circ} P<0.01,{ }^{\circ} P<0.005$

cantly $(P<0.005)$ after $15 \mathrm{~min}$, and remained significantly elevated at $180 \mathrm{~min}$, under control conditions $(236 \pm 67 \%$, mean $\pm \mathrm{SD}, n=3)$ as well as during chronic aspirin treatment $(237 \pm 64 \%$, mean $\pm \mathrm{SD}, n=9$ ) (not shown).

\section{DISCUSSION}

Among numerous substances inhibiting platelet function, aspirin is unique in causing an irreversible defect persisting for the life-span of the exposed platelets. The mechanism underlying this long-lasting defect involves acetylation by aspirin of the active site of platelet cyclooxygenase, which results in irreversible inactivation of the enzyme (2). In healthy subjects, acetylation of platelet cyclooxygenase by oral aspirin is dose-dependent and cumulative with repeated drug administration (14).

The results of the present study demonstrate the dose dependence, cumulative nature, and selectivity of the inhibition by oral aspirin of $\mathrm{TXB}_{2}$ production in whole blood clotting. This rather simple ex vivo model perhaps mimics the in vivo situation more closely than conventional studies carried out in platelet-rich plasma with the addition of exogenous stimuli $(7,10)$. During whole blood clotting thrombin is the major factor responsible for platelet aggregation and release, and the time course of its formation (15) is quite similar to that of $\mathrm{TXB}_{2}$ in healthy subjects (7).

Our finding that a single $100-\mathrm{mg}$ dose of aspirin causes a ceiling inhibitory effect on platelet $\mathrm{TXB}_{2}$ production would suggest that currently used antithrombotic doses (16) are supramaximal with respect to the antiplatelet effect of the drug. One possible interpretation of the reportedly limited efficacy of aspirin, used as an antithrombotic agent, might be related to concomitant inhibition of platelet $\mathrm{TXA}_{2}$ formation and vascular production of $\mathbf{P G I}_{2}$, a vasodilator and inhibitor of platelet aggregation (3). As a consequence, numerous recent studies have addressed the question of how to dissociate platelet from vascular effects of the drug. Although Masotti et al. (17) found no inhibition of circulating $\mathrm{PGI}_{2}$-like activity measured in healthy volunteers following single aspirin doses of 2 and 2.5 $\mathrm{mg} / \mathrm{kg}$ (17), this finding has not been substantiated by other investigators studying ex vivo $\mathrm{PGI}_{2}$ production by human venous biopsies $(4,18)$. One basic assumption underlying these studies is that $\mathbf{P G I}_{2}$ is a physiologically important circulating antiplatelet hormone in man, as originally suggested by Gryglewski et al. (19) and Moncada et al. (20). However, the recent measurement of endogenous rate of secretion (21), peripheral plasma concentration and $t_{1 / 2}(9,22)$, and basal pulmonary formation of $\mathrm{PGI}_{2}$ in healthy man (23) are consistent with a local rather than systemic nature of $\mathrm{PGI}_{2}$ action.

The rationale of our approach was: $(a)$ the repeated use of daily low-dose aspirin (as defined by the doseeffect relationship), causing greater percentage reduction of $\mathrm{TXB}_{2}$ production than daily platelet turnover, should virtually abolish this modulatory pathway; (b) selectivity of this pharmacologic effect should be sought for in clinically relevant areas of cyclooxygenase activity i.e. in well defined targets of aspirin action. Our finding of cumulative inhibition of platelet $\mathrm{TXB}_{2}$ production by daily low-dose aspirin is consistent with previous demonstration by Burch et al. (14) of cumulative acetylation of platelet cyclooxygenase by a daily dose of $20 \mathrm{mg}$. Greater than $95 \%$ reduction of platelet $\mathrm{TXB}_{2}$ production could be maintained on a 
long-term basis, during daily aspirin intake of 0.45 $\mathrm{mg} / \mathrm{kg}$ in healthy subjects. However, since this effect is dependent upon platelet turnover as well as aspirin sensitivity of platelet and megakaryocyte cyclooxygenase, the adequacy of this therapeutic regimen might vary in different disease states. We suggest that this can be tested in each individual patient by the use of serum $\mathrm{TXB}_{2}$ measurements before and during aspirin therapy with negligible blood loss, thus allowing the minimal effective dose of the drug to be established and periodically monitored.

Following cessation of chronic aspirin therapy, platelet $\mathrm{TXB}_{2}$ production returned toward control values at a substantially similar rate as after a single dose of the drug (7). Thus, it would appear that this therapeutic regimen does not affect platelet turnover nor thrombin-induced activation of newly released platelets.

Previous investigators have suggested that the therapeutic benefit of aspirin as an antithrombotic agent is restricted to men $(24,25)$. In our study, we found no obvious difference in the extent, duration and selectivity of aspirin effects between healthy men and women.

Evidence was presented that a daily administration of aspirin $0.45 \mathrm{mg} / \mathrm{kg}$ for $1-4 \mathrm{wk}$ does not reduce the urinary excretion of $\mathrm{PGE}_{2}, \mathrm{PGF}_{2 \alpha}$, and 6-keto-PGF $\mathrm{P}_{1 \alpha}$. Since these reflect, within limits, the renal synthesis of $\mathrm{PGE}_{2}, \mathrm{PGF}_{2 \alpha}(11)$, and $\mathrm{PGI}_{2}(9)$, respectively, these results suggest that medullary and/or cortical sites of cyclooxygenase are not inhibited by low-dose aspirin in healthy subjects. Since $\mathrm{PGI}_{2}$ biosynthesis has been described in human renal medullary and cortical microsomes $(26)$, it is not clear to what extent urinary 6 keto-PGF $F_{1 \alpha}$ reflects a vascular vs. nonvascular origin within the kidney. Although urinary collection periods $<7 \mathrm{~h}$ were not investigated, because of lower reproducibility, it can not be excluded that low-dose aspirin might reversibly inhibit renal sites of cyclooxygenase by $20-30 \%$. In fact, our results are compatible with either no inhibitory effect or with a partial inhibition only lasting 2-3 h following aspirin administration. However, the coefficients of variation of urinary $\mathrm{PGE}_{2}$, $\mathrm{PGF}_{2 \alpha}$, and 6-keto-PGF ${ }_{1 \alpha}$ excretion, measured during the control period, allow us to conclude that if such transient inhibition indeed occurred it was fully reversible and not cumulative. The finding of $40-60 \%$ reduction of urinary $\mathrm{PGE}_{2}, \mathrm{PGF}_{2 \alpha}$, and 6-keto- $\mathrm{PGF}_{1 \alpha}$ excretion following daily administration of a higher dose of aspirin in two of the same subjects indicates adequacy of the experimental conditions used to monitor aspirin effects on renal PG-synthesis. That renal $\mathrm{PGI}_{2}$ formation was unaffected by chronic use of lowdose aspirin was further substantiated by the furosemide studies. We have recently demonstrated that fu- rosemide-induced renin release is associated with increased renal $\mathrm{PGI}_{2}$ formation and suggested that $\mathrm{PGI}_{2}$ is a local modulator of juxtaglomerular function in man (9). The finding of a normal pattern of furosemideinduced increase of renin release and urinary 6-ketoPGF $_{1 \alpha}$ excretion after 3-4 wk of aspirin treatment further indicates that renal $\mathrm{PGI}_{2}$-producing cells are readily activable at a time of virtually complete suppression of platelet cyclooxygenase activity. Since acutely reduced renal PG-synthesis can adversely affect renal function in a number of disease states characterized by sodium depletion, hypotension or ineffective circulatory volume (27), one might anticipate a lower incidence of renal side-effects in these patients by the use of low-dose aspirin, as defined in the present study. The use of anti-platelet agents in nephrology (28) might represent a special case for testing this hypothesis.

Furthermore, by not interfering with furosemideinduced renal $\mathrm{PGI}_{2}$ formation low-dose aspirin might have an additional advantage over high-dose aspirin in patients chronically treated with both drugs. Approximately $30 \%$ of patients recovered from myocardial infarction, studied by the Aspirin Myocardial Infarction Study Research Group, were reported to be on diuretics and possibly other drugs requiring intact vascular PG synthesis (29). The finding that low-dose aspirin does not affect renal $\mathbf{P G I}_{2}$ synthesis does not necessarily imply a similar selectivity in other vascular districts. However, it provides a rationale for further studies in clinically relevant areas.

We conclude that in healthy subjects: $(a)$ aspirin causes a dose-dependent (in the range 12 to $100 \mathrm{mg}$ ) inhibition of platelet $\mathrm{TXA}_{2}$ production, with no obvious sex-related difference; $(b)$ the inhibitory effect of low-dose $(0.45 \mathrm{mg} / \mathrm{kg}$ per $\mathrm{d})$ aspirin is cumulative upon repeated administration on platelet $\mathrm{TXA}_{2}$ but not on renal PG synthesis; (c) during chronic low-dose aspirin therapy, renal $\mathbf{P G I}_{2}$-producing cells are readily activable by furosemide, at a time of virtually complete suppression of platelet cyclooxygenase activity.

\section{ACKNOWLEDGMENTS}

We wish to thank Drs. P. Cattani, G. Ciabattoni, P. Minuz, A. Pierucci, F. Pugliese, and M. A. Satta, the medical students and nurses of the Catholic University School of Medicine for their generous cooperation throughout the studies; Ms. Angelamaria Zampini for expert editorial assistance; Dr. J. E. Pike for several generous gifts of PG and $\mathrm{TXB}_{2}$; Dr. M. J. Dunn and Dr. L. Caprino for a gift of anti-TXB $\mathbf{B}_{2}$ sera; Dr. J. Rokach for a gift of $\mathrm{LTC}_{4}$ and $\mathrm{LTD}_{4}$.

This study was supported by grants from Consiglio $\mathrm{Na}$ zionale delle Ricerche (80.00351.86 of Progetto Finalizzato Tecnologie Biomediche, Subprogetto CHIM-2, and 80.00545.04 and 81.00321.04 of Neuroendocrinopharmacology Research Unit UCSC). 


\section{REFERENCES}

1. Patrignani, P., P. Cattani, P. Minuz, and C. Patrono. 1981. Low-dose aspirin: how low, how often? Clin. Res. 29: 343A (Abstr.).

2. Roth, G. J., N. S. Stanford, and P. W. Majerus. 1975. Acetylation of prostaglandin synthetase by aspirin. Proc. Natl. Acad. Sci. U.S.A. 72: 3073-3076.

3. Flower, R. J., S. Moncada, and J. R. Vane. 1980. Analgesic-antipyretics and anti-inflammatory agents. In The Pharmacological Basis of Therapeutics. A. Goodman Gilman, L. S. Goodman, and A. Gilman, editors. MacMillan Publishing Co., New York. 6th edition, 682728.

4. Preston, F. E., S. Whipps, C. A. Jackson, A. J. French, P. J. Wyld, and C. J. Stoddard. 1981. Inhibition of prostacyclin and platelet thromboxane $\mathbf{A}_{2}$ after low-dose aspirin. N. Engl. J. Med. 304: 76-79.

5. Bianchi Porro, G., I. Caruso, G. Ciabattoni, P. Patrignani, C. Patrono, and F. Pugliese. 1981. Comparative effects of aspirin and diflunisal on platelets and gastric prostaglandin-synthetase in humans. $\mathrm{Br}$. J. Pharmacol. 72: 141P-142P.

6. Plotz, P. H., and R. P. Kimberly. 1981. Acute effects of aspirin and acetaminophen on renal function. Arch. Intern. Med. 141: 343-348.

7. Patrono, C., G. Ciabattoni, E. Pinca, F. Pugliese, G. Castrucci, A. De Salvo, M. A. Satta, and B. A. Peskar. 1980. Low dose aspirin and inhibition of thromboxane $\mathrm{B}_{2}$ production in healthy subjects. Thromb. Res. 17: 317327.

8. Ciabattoni, G., F. Pugliese, G. A. Cinotti, G. Stirati, R. Ronci, G. Castrucci, A. Pierucci, and C. Patrono. 1979. Characterization of furosemide-induced activation of the renal prostaglandin system. Eur. J. Pharmacol. 60: 181-187.

9. Patrono, C., F. Pugliese, G. Ciabattoni, P. Patrignani, A. Maseri, S. Chierchia, B. A. Peskar, G. A. Cinotti, B. M. Simonetti, and A. Pierucci. 1982. Evidence for a direct stimulatory effect of prostacyclin on renin release in man. J. Clin. Invest. 69: 231-239.

10. Patrono, C., G. Ciabattoni, F. Pugliese, E. Pinca, G. Castrucci, A. De Salvo, M. A. Satta, and M. Parachini. 1980. Radioimmunoassay of serum thromboxane $B_{2}$ : a simple method of assessing pharmacologic effects on platelet function. Adv. Prostaglandin Thromboxane Res. 6: 187-191.

11. Frölich, J. C., T. W. Wilson, B. J. Sweetman, M. Smigel, A. S. Nies, K. Carr, J. T. Watson, and J. A. Oates. 1975. Urinary prostaglandins. Identification and origin. $J$. Clin. Invest. 55: 763-770.

12. Ciabattoni, G., F. Pugliese, M. Spaldi, G. A. Cinotti, and C. Patrono. 1979. Radioimmunoassay measurement of prostaglandins $\mathrm{E}_{2}$ and $\mathrm{F}_{2 \alpha}$ in human urine. J. Endocrinol. Invest. 2: 173-182.

13. Haber, E., T. Koerner, L. B. Page, B. Kliman, and A. Purnode. 1969. Application of a radioimmunoassay for angiotensin I to the physiologic measurement of plasma renin activity in normal human subjects. J. Clin. Endocrinol. 29: 1349-1355.

14. Burch, J. W., N. Stanford, and P. W. Majerus. 1978. Inhibition of platelet prostaglandin synthetase by oral aspirin. J. Clin. Invest. 61: 314-319.

15. Schuman, M. A., and S. P. Levine. 1980. Relationship between secretion of platelet factor 4 and thrombin generation during in vitro blood clotting. J. Clin. Invest. 65: 307-313.

16. Passamani, E. R. 1980. Summary of ongoing clinical trials of platelet-active drugs in cardiovascular disease. Circulation. 62 (Suppl. V): 106-110.

17. Masotti, G., G. Galanti, L. Poggesi, R. Abbate, and G. G. Neri Serneri. 1979. Differential inhibition of prostacyclin production and platelet aggregation by aspirin. Lancet. II: 1213-1216.

18. Hanley, S. P., J. Bevan, S. R. Cockbill, and S. Heptinstall. 1981. Differential inhibition by low-dose aspirin of human venous prostacyclin synthesis and platelet thromboxane synthesis. Lancet. I: 969-971.

19. Gryglewski, R. J., R. Korbut, and A. Ocetkiewicz. 1978. Generation of prostacyclin by lungs in vivo and its release into the arterial circulation. Nature (Lond.). 273: 765-767.

20. Moncada, S., R. Korbut, S. Bunting, and J. R. Vane. 1978. Prostacyclin is a circulating hormone. Nature (Lond.). 273: 767-768.

21. FitzGerald, G. A., A. R. Brash, P. Falardeau, and J. A. Oates. 1981. Estimated rate of prostacyclin secretion into the circulation of normal man. J. Clin. Invest. 68: 12721276.

22. Christ-Hazelhof, E., and D. H. Nugteren. 1981. Prostacyclin is not a circulating hormone. Prostaglandins. 22: 739-746.

23. Edlund, A., W. Bomfim, L. Kaijser, C. Olin, C. Patrono, E. Pinca, and $\AA$. Wennmalm. 1981. Pulmonary formation of prostacyclin in man. Prostaglandins. 22: 323332.

24. Harris, W. H., E. W. Salzman, C. A. Athanasoulis, A. C. Waltman, and R. W. De Sanctis. 1977. Aspirin prophylaxis of venous thromboembolism after total hip replacement. N. Engl. J. Med. 297: 1246-1249.

25. The Canadian Cooperative Study Group. 1978. A randomized trial of aspirin and sulfinpyrazone in threatened stroke. N. Engl. J. Med. 299: 53-59.

26. Hassid, A., and M. J. Dunn. 1980. Microsomal prostaglandin biosynthesis of human kidney. J. Biol. Chem. 255: 2472-2475.

27. Dunn, M. J., and E. J. Zambraski. 1980. Renal effects of drugs that inhibit prostaglandin synthesis. Kidney Int . 18: 609-622.

28. Editorial. 1981. Anti-platelet agents in nephrology. Lancet. I: 426-427.

29. Aspirin Myocardial Infarction Study Research Group. 1980. A randomized, controlled trial of aspirin in persons recovered from myocardial infarction. JAMA (J.Am. Med. Assoc.). 243: 661-669. 